\title{
Serial abdominal closure with Gore-tex mesh and Rives-Stoppa for an open abdomen secondary to intra-abdominal hypertension in burns
}

\author{
R Raja Shanmugakrishnan, Charles Yuen Yung Loh, Abhijeet Wakure, Naguib El-Muttardi \\ St Andrew's Centre for Burns and Plastic Surgery, Broomfield Hospital, Chelmsford, Essex, CM1 7ET, UK
}

Address for correspondence: Dr. Charles Yuen Yung Loh, St Andrew's Centre for Burns and Plastic Surgery, Broomfield Hospital, Court Road, Chelmsford, Essex, CM1 7ET, UK. E-mail: chloh_yy@hotmail.com

\section{ABSTRACT}

Intra-abdominal hypertension (IAH) leading to abdominal compartment syndrome (ACS) commonly occurs in major burns. To relieve the excess pressure, decompressive laparotomy is done which can lead to an open abdomen. Closure of the abdomen after a decompressive laparotomy is very difficult with bowel oedema. We describe our technique of closing the open abdomen in such situations with a combination of serial abdominal wall closure with a layered mesh and the Rives-Stoppa component separation technique.

\section{KEY WORDS}

Abdominal compartment syndrome; abdominal hypertension; bogota; burn abdomen; component separation; goretex mesh; Intra-abdominal hypertension; mesh repair; open abdomen; postburn; Rives-Stoppa; PTFE mesh; polytetrafluoroethylene

\section{INTRODUCTION}

ntra-abdominal

hypertension

(IAH)

leading to abdominal compartment syndrome (ACS) commonly occurs in major burns due to extensive fluid resuscitation, thick eschars over the abdomen and sepsis. ${ }^{[1]}$ To relieve the excess pressure, decompressive laparotomy is done which can lead to an open abdomen. Closure of the abdomen after a decompressive laparotomy is very difficult with bowel oedema and expedient closure results in increased pressure again and multi-organ failure. Keeping the abdomen open is fraught with

\begin{tabular}{|l|l|}
\hline \multicolumn{2}{|c|}{ Access this article online } \\
\hline Quick Response Code: & Website: \\
\hline & www.ijps.org \\
\cline { 2 - 2 } & Dol: \\
\hline
\end{tabular}

fluid loss, temperature loss, desiccation of the bowels leading to enterocutaneous fistula and loss of abdominal domain, thus increasing the morbidity and mortality for the patient. We describe how we managed a major burn with IAH and a combination of techniques for safe closure of an open abdomen after the decompression of IAH.

\section{CASE REPORT}

A 20 -year-old woman sustained $48 \%$ deep burns with inhalational injury while cooking. She was resuscitated,

This is an open access journal, and articles are distributed under the terms of the Creative Commons Attribution-NonCommercial-ShareAlike 4.0 License, which allows others to remix, tweak, and build upon the work non-commercially, as long as appropriate credit is given and the new creations are licensed under the identical terms.

For reprints contact: reprints@medknow.com

How to cite this article: Shanmugakrishnan RR, Yung Loh CY, Wakure A, El-Muttardi N. Serial abdominal closure with Gore-tex mesh and Rives-Stoppa for an open abdomen secondary to intraabdominal hypertension in burns. Indian J Plast Surg 2018;51:324-6. 
and the all deep burns were excised and allografted on the $3^{\text {rd }}$ day. She later underwent sandwich grafting on days 6, 18 and 27 post-burns. Most of the grafts had obtained except for a few areas which healed conservatively. She developed pain and tenderness in the right upper quadrant of her abdomen 32 days after the burn. Contrast-enhanced computed tomography (CECT) scan showed free fluid in the abdomen. As the pain increased, CECT scan was repeated on day 37 post-burns which showed bowel and mesentery oedema and increased free fluid in the abdomen. Gastroscopy and colonoscopy were not contributory. Hence, diagnostic laparoscopy was then planned. On inserting the trocar into the abdomen, insufflation of pneumoperitoneum could not be done, as the intra-abdominal pressure (IAP) was $22 \mathrm{~mm} \mathrm{Hg}$ indicating IAH. Decompressive laparotomy was done immediately to prevent the ACS. Laparotomy revealed bowel and mesentery oedema and an old perforation in the stomach which was sealed by the omentum. Colonic biopsies revealed cytomegalovirus infection of the colon. The abdomen was temporarily closed by negative-pressure wound therapy (NPWT). Peritoneal lavage was done twice later due to persistent necrotic tissues in the abdomen. 14 days after laparotomy, the oedema settled and she was considered fit for closing the abdomen. Gore-tex mesh was sutured on the fascia both sides, pulled together (PTFE polytetrafluroethylene) and sutured in the midline. NPWT was applied over this to approximate the wound [Figure 1].

The patient was taken to the theatre every week, the mesh was progressively approximated, and NPWT applied over this for 4 weeks. Serial weekly excision of the Gore-tex mesh was performed with gradual advancement of the

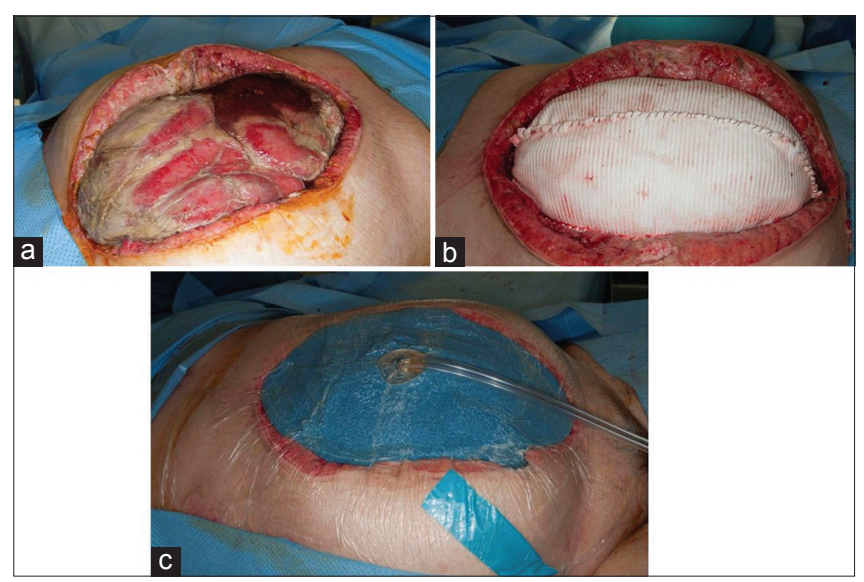

Figure 1: (a) Photograph of the open abdomen after release for intra-abdominal hypertension. (b) Coverage of the open abdomen with a sheet of Gore-tex mesh with suturing to the edges of the separated muscle. (c) Application of a vacuum-assisted closure dressing over the Gore-tex mesh as a temporary closure method muscles and fascia to the midline on either side. After the fascia and the skin could be approximated, a definite closure was done using the Rives-Stoppa technique. Here, both the posterior rectus sheaths were brought together and sutured in the midline. A prolene mesh was placed below the rectus muscles, and the anterior rectus sheath and the skin were sutured in the midline. At 1 year after the last operation, all her wounds healed and she had no hernia [Figure 2].

\section{DISCUSSION}

Ivy et al. ${ }^{[2]}$ have noted IAH in $70 \%$ of patients with major burns. Increase in IAP occurs when there is an increased intra-abdominal content (free fluid and bowel oedema due to inappropriate resuscitation and sepsis) and due to a decrease in abdominal wall compliance ${ }^{[3]}$ (abdominal eschars and agitation). Increase in IAP usually occurs early due to over-resuscitation, abdominal eschars and agitation. In our case, it was late due to sepsis. The normal IAP is between sub-atmospheric levels to $0 \mathrm{~mm} \mathrm{Hg}$ and can rise to $5-7 \mathrm{~mm} \mathrm{Hg}$ in the critically ill. IAH is defined when there is a sustained rise in IAP $>12 \mathrm{~mm} \mathrm{Hg}$. ACS is defined as a sustained increase in IAP $>20 \mathrm{~mm} \mathrm{Hg}$ with the organ failure. ${ }^{[4]}$ ACS can lead to decreased venous return and cardiac output, reduced blood flow to the kidneys leading to oliguria and anuria, reduced blood flow to the bowels resulting in increased translocation of bacteria from the gut into the blood, reduced gut motility and liver dysfunction. It also increases intrathoracic pressure and intracranial pressure, hypoxia and hypercarbia leading to

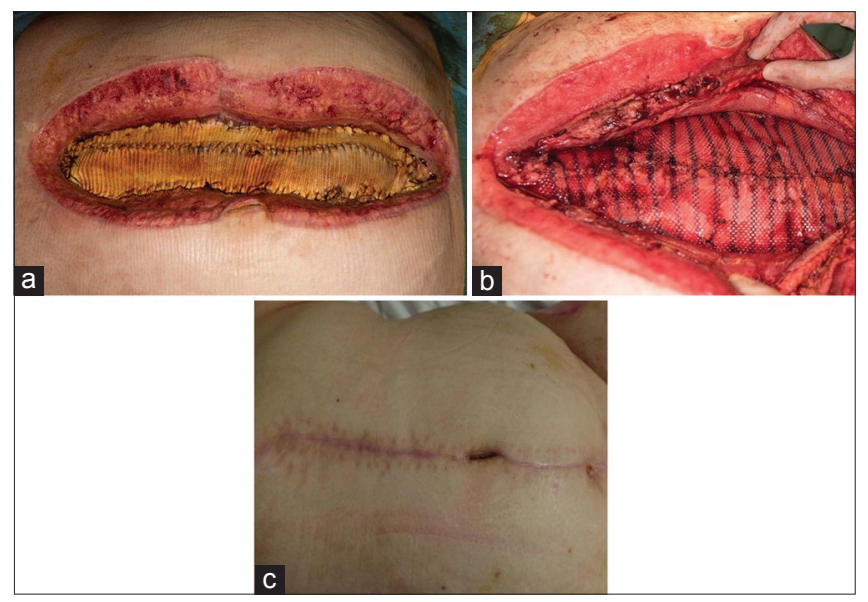

Figure 2: (a) Serial weekly excision of Gore-tex mesh and advancement of edges of muscle in keeping with the patient constitution and stability. (b) Final component separation using the Rives-Stoppa technique in combination with ultrapro mesh for reinforcement in a subrectus fashion with approximation of the tissues. (c) Photograph of the abdomen at 1-year follow-up 
death. ${ }^{[5]}$ Thus, IAP needs to be measured at least every $2 \mathrm{~h}$ in major burns. They can be done directly by an intra-abdominal catheter inserted for ascites drainage, peritoneal dialysis or laparoscopy or they can be done indirectly through the urinary bladder, rectum and uterus. Detecting IAH necessitates treating the cause, namely, paralysing the patient with agitation, diuresis with increased fluids, escharotomies with abdominal eschars and treating sepsis. When the patient is refractory to the above treatment, decompressive laparotomy is done.

To prevent fluid loss, temperature loss, enterocutaneous fistula leading on to desiccation of bowels and loss of abdominal domain, the abdomen needs to be closed soon. The methods to close the open abdomen can be broadly divided into those that do not close the fascia and those that aim for a delayed fascial closure. ${ }^{[6]}$ The former includes NPWT, skin approximation with towel clips, allowing for granulation and grafting. These techniques are used when the patient is in poor health and aim to treat a planned ventral hernia later. However, repair of a ventral hernia later can be difficult due to the retraction of the fascia and loss of tone of the rectus muscle. The latter techniques include dynamic retention sutures, Wittmann Patch, Bogota bag technique and using a Gore-tex mesh. The former techniques involve suturing material to the fascia both sides and closing progressively in the midline. NPWT is usually applied over it. Dynamic retention sutures can lead to fascial necrosis. ${ }^{[7]}$ Wittman patch is a Velcro-like device that can be easily closed in the middle. ${ }^{[8]}$ This is quite costly and not available everywhere.

The Bogota technique involves suturing a plastic sheet to the fascia and progressively closing in the midline and is commonly used as it is very cheap. ${ }^{[9]}$ We used Gore-tex mesh because it can be safely applied over the bowels and is stronger than the plastic sheet used in Bogota technique. ${ }^{[1]}$ NPWT above it helps to get the skin together and eases nursing care. After the fascia comes together, a definitive abdominal closure is done as the Gore-tex mesh left alone will cause infection. Rives-Stoppa technique ${ }^{[10]}$ is a gold standard technique for the closure of ventral abdominal defects. As the posterior rectus sheath is closed, a prolene mesh can be used instead of this technique.

\section{CONCLUSION}

This article highlights the need to watch out for IAH and highlights a possible method of closing an open abdomen after a decompressive laparotomy for ACS after a severe burn.

\section{Declaration of patient consent}

The authors certify that they have obtained all appropriate patient consent forms. In the form, the patient has given her consent for her images and other clinical information to be reported in the journal. The patient understand that name and initial will not be published and due efforts will be made to conceal identity, but anonymity cannot be guaranteed.

\section{Financial support and sponsorship Nil.}

\section{Conflicts of interest}

There are no conflicts of interest.

\section{REFERENCES}

1. Vertrees A, Kellicut D, Ottman S, Peoples G, Shriver C. Early definitive abdominal closure using serial closure technique on injured soldiers returning from Afghanistan and Iraq. J Am Coll Surg 2006;202:762-72.

2. Ivy ME, Atweh NA, Palmer J, Possenti PP, Pineau M, D'Aiuto M, et al. Intra-abdominal hypertension and abdominal compartment syndrome in burn patients. J Trauma 2000;49:387-91.

3. Papavramidis TS, Marinis AD, Pliakos I, Kesisoglou I, Papavramidou N. Abdominal compartment syndrome - Intraabdominal hypertension: Defining, diagnosing, and managing. J Emerg Trauma Shock 2011;4:279-91.

4. Coccolini F, Roberts D, Ansaloni L, Ivatury R, Gamberini E, Kluger $\mathrm{Y}$, et al. The open abdomen in trauma and non-trauma patients: WSES guidelines. World J Emerg Surg 2018;13:7.

5. Maerz L, Kaplan LJ. Abdominal compartment syndrome. Crit Care Med 2008;36:S212-5.

6. Boele van Hensbroek P, Wind J, Dijkgraaf MG, Busch OR, Goslings JC. Temporary closure of the open abdomen: A systematic review on delayed primary fascial closure in patients with an open abdomen. World J Surg 2009;33:199-207.

7. Koniaris LG, Hendrickson RJ, Drugas G, Abt P, Schoeniger LO. Dynamic retention: A technique for closure of the complex abdomen in critically ill patients. Arch Surg 2001;136:1359-62.

8. Tieu BH, Cho SD, Luem N, Riha G, Mayberry J, Schreiber MA, et al. The use of the Wittmann patch facilitates a high rate of fascial closure in severely injured trauma patients and critically ill emergency surgery patients. J Trauma 2008;65:865-70.

9. Kirshtein B, Roy-Shapira A, Lantsberg L, Mizrahi S. Use of the "Bogota bag" for temporary abdominal closure in patients with secondary peritonitis. Am Surg 2007;73:249-52.

10. Forte A, Zullino A, Manfredelli S, Montalto G, Covotta F, Pastore $\mathrm{P}$, et al. Rives technique is the gold stardard for incisional hernioplasty. An institutional experience. Ann Ital Chir 2011;82:313-7. 